\title{
A participação do público no webjornalismo
}

\author{
Claudia Irene de Quadros ${ }^{1}$ \\ Universidade Tuiuti do Paraná \\ claudiaquadros@hotmail.com
}

\begin{abstract}
Resumo: A participação do público no jornalismo realizado na rede mundial de computadores e o impacto causado na mídia tradicional são motivos desse artigo. Há dez anos o jornalismo digital prometia um diário na web cada vez mais interativo. Hoje a interatividade ainda não alcançou a sua plenitude no webjornalismo, mas entre as experiências já realizadas no ciberespaço é possível destacar algumas que provocaram transformações em todos os meios de comunicação, inclusive nos diários digitais. Aqui não se pretende analisar formas de navegação no jornalismo digital nesta última década, mas repercutir práticas interativas que propiciaram tais mudanças. Entre as mais recentes, está o blog, que despertou a atenção do internauta por sua informalidade e pelo livre fluxo de informação, além de inspirar outras formas de um jornalismo mais participativo. No open source journalism, por exemplo, o usuário também pode escrever uma notícia. Assim como em um software de fonte aberta, onde é possível acrescentar, alterar ou corrigir um dado, o público tem um certo domínio sobre a informação jornalística.
\end{abstract}

Palavras-chave: web, jornalismo; open source.

Abstract: This essay is concerned with the participation of the audience in the international computer web and the impact it causes in traditional media. Ten years ago, digital journalism promised a web diary each day more interactive. Today, interactivity still has not reached its potential in web journalism, but, among the experiences in cyberspace, it is possible to find some really challenging ones within means of communication, including digital diaries. The intention of this essay is not to analyze navigation ways in digital journalism in the last decade but pointing out interactive practices that provoke changes. Among the most recent ones is the blog, which has caught attention because of its informality and free flux of information, besides inspiring other forms of more participative journalism. Within open source journalism, for instance, users can also include news. As well as in free source software, in which it is possible to add, alter or correct data, audience is given a certain amount of power over journalistic information.

Key words: Web; journalism; open source.

\footnotetext{
${ }^{1}$ Doutora em Jornalismo pela ULL (Espanha). Professora do Programa MCL - Mestrado em Comunicação e Linguagens da Universidade Tuiuti do Paraná. Esse artigo foi apresentado no III Encontro de Pesquisadores em Jornalismo, Florianópolis, nov. de 2005.
} 
Resumen: La participación del público en el periodismo hecho en la red de las redes y el impacto sobre los medios convecionales son motivos del artículo. Hace diez años el periodismo digital prometía un diario cada vez más interactivo en la Web. Hoy la interactividad aún no ha logrado su plenitud en el periodismo Web, pero entre los experimentos realizados en el ciberespacio es posible destacar algunos que provocaron transformaciones en todos los medios de comunicación, incluso en los diarios digitales. Aquí no se pretende analizar las formas de navegación en el periodismo digital en la última década, pero repercutir prácticas interactivas que proporcionaron esos muchos cambios. Entre las más nuevos experimentos, está el blog, que ha llamado la atención del internauta por su informalidad y por el libre flujo de información, además de inspirar otras formas de un periodismo más colaborativo. En el open source journalism, por ejemplo, el usuario también puede escribir una noticia. Así como en un programa informático de fuente abierta, donde es posible acrecentar, alterar o corregir un dato, el público tiene un cierto dominio respecto a la producción periodística.

Palabras-clave: open source; periodismo; web.

Resumé: La participation du public dans le journalisme fait dans le réseau mondial d'ordinateurs, et l'impact causé dans lés médias traditionnels sont les thèmes de cet article. Il ya dix ans le journalisme digital promettait un journal sur le Web, qui serait de plus en plus interactif. À présent $l^{\prime}$ interactivité $n^{\prime}$ a pas atteint son apogée encore dans le Web journalisme, mais entre les expériences déjà accomplies dans le cyberespace on peut souligner quelques-unes qui ont déjà produit des transformations dans tous les médias, même dans les journaux sur le Web. Le but du texte n' est pas analyser des formes de navigation du journalisme digital, au cours de la dernière décennie, mais considérer des pratiques interactives qui ont fait possibles de tels changements. Entre les plus récentes, on trouve le blog, qui a réveillé l'attention de l'internaute à cause de son informalité, et en raison du livre flux $d$ 'information. Le blog a aussi inspiré d' autres formes de journalisme plus participatif. Dans le open source journalism, par exemple, l'utilisateur peut aussi écrire des nouvelles. Tout comme dans un logiciel open source, où il est possible ajouter, modifier ou corriger une donnée, le public a quelque contrôle sur l' information journalistique

Mots-clé: open source; journalisme; Web. 


\section{Introdução}

Há dez anos o jornalismo digital trouxe uma esperança em tornar os meios de comunicação mais democráticos com a proliferação dos diários na web, pois era prometida uma interação plena do internauta que o transformaria em produtor da notícia. Hoje, a troca da comunicação e a inversão de papéis entre consumidores e produtores da notícia raramente ocorre nos jornais digitais, ao contrário do que professavam teóricos do ciberespaço. De 1995 a 2005, contudo, o impacto das tecnologias avançadas da comunicação se refletiu nas rotinas produtivas de todos os meios de comunicação de massa, e os jornais digitais evoluíram apesar da inaptidão da maioria deles com relação à interatividade.

Neste ínterim, no qual houve euforia e depois estagnação do jornalismo digital, surgem os blogs para reanimar os usuários da Internet com um livre fluxo de informação. A informalidade, uma característica evidente dos blogs, também incentivou a participação do leitor, elevando-o, de fato, à categoria de usuário. De acordo com o site Technorati (www.technorati.com), são criados por dia 80 mil blogs dos mais variados estilos e a estimativa do início do segundo semestre de 2005 já revela um número surpreendente: mais de 14 milhões de blogs fazem parte da blogosfera. Nesse contexto, em que o público passa a ter outras alternativas para buscar e divulgar um fato, o papel dos gatekeepers - conceito criado por Kurt Lewin para se referir aos editores que decidem o que deve ou não fazer parte do fluxo de informação - é reavaliado para explorar o potencial comunitário e agregador, como define Lemos (2002), da nova tecnologia, garantindo a audiência de internautas que, de certa forma, têm mais direitos do que deveres na rede das redes. Neste sentido, o usuário pode interagir de forma efetiva e a seu bel-prazer no momento que troca informações em um meio descentralizado e sem muitas regras definidas. Assim, ao exercer o seu poder na Internet, também decide novos rumos da mediação. O controle centralizado dos meios massivos, que comunicam de um para 
muitos, dá lugar a outras formas de mediação que podem ser democráticas ou não. Para Vaz (2004), esses novos tipos de mediações devem ser pesquisados, aproveitando as potencialidades da Internet e, como destaca Wolton, preservando o homem de suas próprias fraquezas, forças e contradições. "Porque só ele sonha o futuro, pensa sua história e dá sentido a sua experiência" (2004: 155).

\section{Da interatividade anunciada às reais práticas interativas}

A forma plural de comunicar na Internet - um para um, muitos para muitos, muitos para um e também de um para muitos - possibilita a participação efetiva de um público outrora passivo e recentemente pseudoativo. Poucos jornais ou revistas na web interagem com o usuário, pois a interatividade propalada por muitos desses meios não passa de um simulacro. Mas, no ciberespaço, as alternativas disponíveis ao usuário permitem que ele tenha voz ativa, alguém que o escute - ainda que isso signifique uma única pessoa - e um lugar para obter informação relevante do seu ponto de vista. Com isso, os meios de comunicação tradicionais e as suas versões digitais voltam a se preocupar com a possível migração de sua audiência para blogs ou outras experimentações interativas na rede mundial dos computadores. Na tentativa de reconquistar e/ou ampliar o seu público, empresários da comunicação olham com mais seriedade as mudanças em seu entorno, buscando adaptar e até criar algumas idéias que atraiam o usuário/leitor/telespectador/ouvinte. No entanto, a preocupação deles pelo público pode ser resumida em um interesse central: o lucro.

A informação é encarada como negócio pelos empresários de comunicação desde o início do século XIX, quando foi possível a profissionalização do jornalista. Neste momento, entretanto, “é preciso dissociar o mais rápido possível a informação que permanece fiel a uma certa filosofia democrática daquela que se ergue antes de tudo de uma lógica instrumental e econômica.” (Wolton, 2004: 154). No ciberespaço, ainda que muitos insistam em tratar a 
informação somente como negócio, a descentralização do meio permite que o internauta encontre, como destacado anteriormente, alternativas para saber mais sobre determinado assunto e sem precisar pagar nada por isso. Dessa forma, ele ganha experiência e torna-se também responsável por mudanças no status quo do jornalismo. Estudos sobre os níveis de interação do usuário da Internet são desenvolvidos em diversos países (Santaella,2004; Primo,1998; Noci, 2004; Salaverría,2004; Johnson, 2001). Aqui, no entanto, a questão não é categorizar como tem navegado o usuário nos diários digitais na última década, mas refletir sobre a participação do público no transcurso de uma história recente da Internet como meio de comunicação. Ainda é muito cedo para uma conclusão definitiva sobre o tema, mas se podem apontar alguns caminhos. Afinal, em dez anos houve tempo para o jornalismo digital ganhar algumas características próprias e avançar, como diria Norbert Elias (1998), a partir de um patrimônio de saber adquirido anteriormente.

No início do boom dos jornais digitais, havia apenas a transposição dos diários impressos para a rede das redes, como destacado em estudos anteriores (Pavlik, 1997; Quadros, 1999; Machado, 2003); logo começou uma tímida exploração da hipermídia em partes de sites jornalísticos que passaram a exibir alguns produtos diferenciados, como atualização de notícias e infografias tridimensionais estáticas e, depois, em movimento. Neste sentido, era uma forma de atender as expectativas de um usuário sedento por encontrar transformações de um meio oriundo da Revolução Digital. Ainda hoje, com o desenvolvimento do jornalismo digital em curso, é comum observar reproduções de idéias que surgem no ciberespaço para cativar e seduzir o usuário. Mas da revolução à evolução, os diários digitais também são modelos para diversos veículos de comunicação. Jornais e revistas impressos, por exemplo, espelham-se na arquitetura web dos sites jornalísticos para atender um leitor cada vez mais sem tempo. Os textos pílulas dispostos para facilitar a leitura lembram links que dão acesso a diversas pequenas janelas contendo, em cada uma delas, uma informação sobre o assunto em pauta. Esses e outros 
meios de comunicação também encontraram na Internet uma maneira de ter mais contato com o público, fazendo do ciberespaço uma mídia complementar. No entanto, vale ressaltar que a fórmula para a interatividade - entendida aqui como troca de informação entre destinador e destinatário da notícia - é buscada por todos os meios de comunicação, inclusive os jornais digitais.

Se por um lado os jornais digitais ainda não encontraram um modo para interagir de forma plena com o usuário, por outro é importante destacar algumas experiências do chamado open source journalism. Semelhante ao sistema de produção de blogs, nesse jornalismo de fonte aberta os usuários de diários e revistas digitais também colaboram com editores no momento de escrever uma reportagem. O termo open source journalism foi usado pela primeira vez em 1999, num artigo de Andrew Leonard, sobre a experiência de uma repórter do Slashdot ${ }^{2}$, que pediu a participação do público para escrever um artigo sobre ciberterrorismo (Leonard, 1999). Desde então os seus usuários têm feito desse site um espaço de democratização do jornalismo.

\subsection{Slashdot}

No Slashdot todos têm direito a informar, não apenas os jornalistas. Um dos criadores do site, Rob Malda (apud Glave, 1999), destaca que os jornalistas decidiram que somente eles podem fazer jornalismo e, normalmente, estão mais preocupados com uma possível perda de espaço de trabalho do que com o público. Para Malda, não importa se o emissor da notícia é jornalista ou não, o essencial está no que o Slashdot representa: o início da era do open source journalism. Neste sentido, salienta-se que na comunicação em redes a sociedade adquire novos comportamentos e valores, provocados por mudanças sociais, políticas, econômicas e culturais, a uma velocidade muito mais rápida do que em outros tempos. Assim, as novas formas de mediação devem ser observadas não só pelos pesquisadores, mas também pelos próprios jornalistas vinculados aos mais diversos meios de comunicação.

${ }_{2}$ A URL do Slashdot, criado em 1997, é www.slashdot.org. 
No caso do Slashdot, o conteúdo também é produzido por seus usuários, anônimos ou não, mas que só conquistam o papel de mediadores quando enviam com freqüência comentários que despertam o interesse do público e agregam valor ao site. Quem prefere enviar uma mensagem anônima é identificado por "anonymous cowards" (AC's), não pode ser mediador, recebe uma pontuação, normalmente, baixa pelo seu comentário e, conseqüentemente, é menos lido. A pontuação para os comentários é feita pelos editores do Slashdot, assim como a escolha dos mediadores e a definição de suas responsabilidades. Um mediador exerce o seu cargo por pouco tempo para salvaguardar a pluralidade de vozes e, neste período, não pode enviar comentário algum para qualquer discussão.

Em uma breve comparação com a mediação exercida por outras mídias, o Slashdot propõe uma fusão de novas e antigas práticas do jornalismo. A diferença está na posição conquistada pelo usuário da Internet, que pode fazer parte do começo ao fim das rotinas produtivas de um jornal, uma revista etc. Nos meios de comunicação tradicionais existem gatekeepers para controlar o fluxo de informação e decidir o que é mais importante para o leitor, enquanto no ciberespaço a descentralização permite que todos participem da construção de uma história. No caso do referido site, os usuários podem enviar comentários classificados por novos gatekeepers menos rigorosos, pois estes disponibilizam na rede todas as informações recebidas. No entanto, a classificação dos comentários já determina um controle, uma proposta de leitura e a falta de igualdade de direitos. O usuário anônimo de certo modo é exposto, porque a sua informação é colocada em dúvida, e pelo baixo índice de leitura de seu comentário fica difícil checar a veracidade do fato, ao contrário do que ocorre quando um jornalista recebe uma informação em off. Os novos gatekeepers, pelo que parece, não percebem esse post como um fato que pode repercutir e desvendar uma história intrincada, deixando transparecer que todas as ações devem sair do caráter privado para o público. Só então é possível premiar com mais responsabilidade o usuário, que ao conquistar o posto de 
mediador exerce, de maneira limitada, a função de uma espécie de ombudsman.

É evidente que há pontos positivos nessas propostas, porque há muito tempo exige-se maior participação do público nos meios de comunicação. A Internet facilitou a troca de informações e conseguiu sair da página web33, servindo também como mídia complementar e impulsionando novos projetos de um jornalismo mais participativo, mas é preciso não se iludir com o determinismo tecnológico. "Se os internautas convencidos de uma Internet democrática querem conservar uma real iniciativa, é preciso aliança entre eles e todas as forças culturais, sociais e políticas que compreenderam que a comunicação é um dos maiores desafios de amanhã”. (Wolton, 2004: 154). Portanto, o importante não está na discussão do papel do jornalista nestas transformações, mas como o esforço coletivo pode tornar viável uma comunicação livre do controle dos atores hegemônicos da economia, política e cultura.

\subsection{Exemplos de um terceiro entorno}

Ao invés de um mundo injusto e assimétrico, onde poucos cidadãos têm benefícios e privilégios, surge a possibilidade de transformá-lo numa ágora renovada para que um público mais amplo tenha direitos iguais no momento de receber ou enviar uma informação. A mídia, quase sempre a primeira a refletir processos sociais, vem procurando adotar práticas comunicacionais democráticas para estabelecer relações com o indivíduo que não pretende se ver diluído pela enorme quantidade de informações disponíveis. Neste sentido, a manipulação dos fatos deve dar lugar a sua transparência também por conta dessas mediações contemporâneas descentralizadas. É óbvio que esse processo é gradativo e nem a velocidade do tempo imposta pela Internet vai mudar o

\footnotetext{
${ }^{3}$ Página tem origem em pagus, que no latim significa campo do camponês. Ressalta-se que o impacto da comunicação em rede tem provocado mudanças em toda a sociedade, não é apenas tecnológico. Para mais detalhes, consulte (Quadros, 2005) “Jornalismo público com a Internet: uma proposta para incentivar a democracia”, apresentado na Alaic.
} 
mundo de forma homogênea com um simples clique no mouse. Pensar desse modo seria ingênuo e utópico. Mas, aos poucos o terceiro entorno, proposto por Echeverría (apud Delarbre, 2001) e constituído por sete tecnologias - o telefone, o rádio, a televisão, o dinheiro eletrônico, as redes telemáticas, a multimídia e o hipertexto - , em todos os espaços e situações, é tratado mais como uma cidade do que um mundo virtual. Para Echeverría, tal medida impede de pensar a Internet apenas como um mercado, pois ao associá-la à cidade imediatamente vem a idéia de democratização e humanização.

Partindo desse contexto, modelos de mediação propostos na Internet ou em outros meios de comunicação podem ser associados para atender necessidades emergentes e estreitar relações com o público. O Civic Journalism, surgido no início dos anos 90 nos Estados Unidos, ganha impulso e muitos adeptos com o trabalho em rede de jornalistas dos mais variados meios e de leitores/ouvintes/telespectadores/usuários. Nesta corrente, o jornalista se apresenta como parcial, defensor e um dos mediadores das necessidades de um público que também tem voz. Com essas evidentes mudanças nas rotinas produtivas, é possível, então, redefinir o papel do jornalista.

De selecionadores da notícia passam a exercer a função de intérpretes e controladores da qualidade com o apoio do público produtor/consumidor, que vem percebendo a dificuldade de narrar uma história e conquistar a confiança de outros receptores com tanta informação, útil e inútil, neste terceiro entorno. Por isso, Robert McChesney apud Beckerman (CJR, 2003) acredita que sites adeptos do open source, como o Indymedia (www.indymedia.org), devem ser elaborados com base nos princípios da transparência. Criado no final da década de 90, o Indymedia incentiva a participação dos cidadãos em todo o processo de produção que experimenta e assume responsabilidades de uma mídia democrática. De passivos a ativos, os consumidores desse site - presente em diversos países, inclusive no Brasil - e de outros que estão surgindo com 
características semelhantes têm a oportunidade de corrigir, alterar, acrescentar ou escrever um novo fato. Nem todos, entretanto, enviam informações interessantes e grande parte do conteúdo considerado duvidoso é questionado pelos próprios participantes, demonstrando que não há necessidade de muitas regras para se obter um posicionamento ético do usuário. Sendo assim, outros meios de comunicação tentam recuperar o contato perdido com as pessoas para reconstruir um jornalismo apropriado para o século XXI, como é enfatizado no Rebuilding Media (www.corante.com/rebuildingmedia, ) - um blog coletivo idealizado por dois americanos, Vin Crosbie e Robert Cauthorn, que já assumiram cargos importantes na mídia norte-americana.

Um outro exemplo que tem despertado interesse de estudiosos e usuários da Internet é o jornal Northwestvoice4, feito por meio de comentários enviados por membros da comunidade de Northwest Bakersfield, na Califórnia. Os melhores comentários são selecionados pelos editores do referido jornal para a publicação da versão impressa, que tem uma tiragem de 28 mil exemplares e já conseguiu faturar 30\% a mais com publicidade desde que esse projeto foi implantado. (observatório de imprensa, 27/07/2004).

O jornal Los Angeles Times também fez uma experiência desse tipo, abrindo a possibilidade para o público reescrever a seção de opinião e o editorial. "A resposta foi massiva, permitindo observar as orientações políticas do público do jornal (...), mas, além das divergências radicais entre conservadores e liberais, o site foi também invadido por bobagens, obscenidades e até imagens pornográficas." (Costa, 2005). Por conta disso, os editores do jornal decidiram fechar essa possibilidade de maior participação do público dois dias após a sua implantação. Robert Barret, gerente do Los Angeles Times Interactive, afirmou que o diário pretende retomar esse projeto, no entanto, vai estudar primeiro uma forma de impedir a ação de vândalos. No Brasil, a livre participação do público também foi interrompida

4 O Northwest voice pode ser acessado na URL http://www.northwestvoice.com/. 
temporariamente pelo jornalista Ricardo Noblat em seu blog, que em julho de 2005 registrou 1.005.194 visitantes únicos (Ips). Alguns usuários estavam impedindo a leitura do blog ao enviar mensagens para atravancar o servidor, atitude que se intensificou com o aumento de denúncias na comissão parlamentar de inquérito (CPI) dos Correios e a renúncia de cargos importantes do governo Lula por conta de escândalos de corrupção.

Soluções tecnológicas para impedir ações de vândalos ou protestos são requisitadas desde o início do boom do webjornalismo. Em 1998, por exemplo, a página inicial da versão digital do The New York Times foi invadida por hackers que colocaram fotos de mulheres nuas no lugar das notícias5; os produtores de conteúdo optaram por suspender temporariamente o acesso de todos os internautas para não comprometer a credibilidade do site. Neste antigo caso e nos outros dois mais recentes, o do Los Angeles Times e do Blog de Noblat, a primeira atitude foi punir todos os usuários/leitores que não puderam acessar o conteúdo por determinado período e/ou enviar novas mensagens. Neste aspecto, dez anos depois do boom do jornalismo digital, é possível afirmar que ainda falta domínio técnico. A perda do controle sobre a informação provoca ações radicais dos homens da mídia e parte do público precisa aprender a participar e ter também consideração por outros usuários e mediadores. Por outro lado, dez anos ainda é pouco tempo para consumidores e produtores -, acostumados com a passividade e a centralização, respectivamente - adotarem novas posturas diante da exigência da redefinição de seus papéis. No ínterim desse esperado amadurecimento de ambos, muitas surpresas podem surgir, tal como aconteceu com a Revolução de Gutenberg. Enquanto isso, a invasão a um site jornalístico pode ser entendida como um ato de vandalismo ou de protesto, dependendo do ponto de vista. Como bem destaca Silva (2000), os donos do poder sabem até que ponto a liberdade do

\footnotetext{
5 Para saber mais sobre o fato da invasão dos hackers na versão digital do The New York Times consulte (Quadros, 2000) “Una discusión ética en los periódicos electrónicos”, disponível em Ámbitos (http://148.215.4.212/rev/168/16800411.pdf).
} 
usuário tem interesse para o seu desenvolvimento econômico e político. Portanto, "quanto mais filtros aparecem (organizações sociais de todos os tipos), mais a influência da mídia encontra contrapoderes”. (2000:27).

Alguns sites de jornalismo de fonte aberta que estão há mais tempo na web experimentam medidas para evitar comprometer a sua credibilidade, exigindo maior compromisso e responsabilidade por parte do público. É o caso do Ohmynews (http://english.ohmynews.com/), da Coréia do Sul. Criado em 2000 por quatro jornalistas, esse site ganhou uma versão internacional em meados de 2004 para aumentar a contribuição dos usuários. O editor Oh Yeonho (apud Kahney:2003), um dos fundadores do OhmyNews, conta que o site parte do princípio de que "todo cidadão pode ser um repórter", colocando o que pessoas julgam ser verdade. Na opinião dele, essas iniciativas de open source mostram que é grande o desejo em dar adeus ao jornalismo do século $\mathrm{XX}$, quando as pessoas só podiam ver as coisas com os olhos de uma mídia conservadora. No entanto, para ser um cidadão-repórter do Ohmynews, é preciso preencher um cadastro minucioso e enviar, por e-mail ou fax, reproduções de documentos de identidade, passaporte e carteira de habilitação. Depois da avaliação e pedido aceito, o cidadão-repórter sempre deve submeter as suas reportagens aos editores do site que, normalmente, editam-nas. "Concordar com o código de ética do OhmyNews é requisito básico para ser aceito como cidadão-repórter" (Brambilha, 2005).

Ao considerar que o texto também é editado nos princípios básicos do jornalismo para facilitar a troca de comunicação, os editores responsáveis pelo OhmyNews reproduzem práticas, agora renovadas, da área. Nesse processo, o cidadão-repórter assume responsabilidades antes exclusivas do jornalista e, a exemplo desse profissional, também enfrenta um certo tipo de censura por parte dos editores. Tocar no assunto da substituição do jornalista por um cidadão repórter ainda provoca muitas polêmicas, sobretudo entre os profissionais mais conservadores, que colocam em dúvida a qualidade de 
conteúdo elaborado por um indivíduo sem preparo. Mas, ao precisar descrever semelhanças produtivas do jornalista com a do cidadão-repórter, aflora a certeza de que a interatividade, ainda não concretizada no jornalismo digital, começa a conquistar níveis mais profundos. Os poucos sites jornalísticos de fonte aberta e os milhares de blogs têm servido de modelos para muitos diários na web e outros meios de comunicação do terceiro entorno quando o assunto é interatividade.

Porém, assim como os primeiros diários digitais eram apenas a reprodução de suas versões impressas, ganhando, num segundo momento, produtos diferenciados com a exploração de recursos hipermidiáticos, a relação interativa entre mediador e usuário vai definindo suas fases nos sites e portais jornalísticos. Na primeira fase, a interatividade é mais uma promessa do que uma realidade. O usuário envia um e-mail à redação digital e não obtém resposta, apenas a disponibilização do seu conteúdo editado em um espaço definido para os leitores tal como ocorre nas seções de cartas dos jornais impressos. Na segunda fase, o usuário tem a oportunidade de escolher mais caminhos possíveis com o uso ainda incipiente do hipertexto. Com sorte, em alguns jornais, ele consegue enviar e-mails diretamente aos jornalistas e receber uma resposta. São oferecidas algumas possibilidades de escolha, normalmente, dispostas em formulários estanques. Na terceira fase, são marcadas conversas esporádicas com jornalistas e personalidades famosas. Mais do que provocar o espírito crítico de internautas inertes, a intenção do mediador é atrair o público. Na quarta fase, na qual já se proliferam os blogs, alguns jornais digitais adotam a possibilidade de enviar comentários sobre os assuntos em pauta. Os comentários são disponibilizados logo abaixo das reportagens. Não há troca de comunicação entre mediadores e usuários, mas o mediador responsável por determinada reportagem pode citar alguma mensagem que desperte o seu interesse. A capacidade de memória do usuário é estendida por meio do banco de dados, que faz o elo entre informações fragmentadas ao relacionar o conhecimento humano. Na quinta fase, o público ganha o direito de produzir 
uma matéria com o apoio do mediador. Os conteúdos podem ser bons ou ruins e o usuário ainda aprende a soltar a voz por muito tempo abafada pelos meios de comunicação de massa. Desse fato, surgem resultados surpreendentes que vão de matérias críticas e construtivas a ações de vandalismo. As primeiras são valorizadas como memória e as segundas são citadas como um poder negativo do usuário sobre a nova mídia. Na quinta fase, o usuário também adquire o direito de disponibilizar conteúdos audiovisuais. Parece mais um paparrazi do que um cidadão-repórter, consciente das suas responsabilidades, como o da sexta fase. Nesta fase, emissores e receptores invertem os papéis para construir de modo interativo uma história. O resultado é bom ou ruim? Neste momento, o mais importante é que dessa relação interativa surgem novas possibilidades que já marcam a evolução do jornalismo digital e de outros meios de comunicação. Cada vez mais, neste sentido, o terceiro entorno de Echeverría deve ser observado em nome da democratização e do livre fluxo de informação. É importante ressaltar que a proposta da tipologia acima não pretende ser conclusiva, pelo fato de a interatividade não ter se concretizado nos jornais digitais, ou estanque - uma vez que sites jornalísticos podem apresentar características de duas ou mais fases-, mas contribuir na análise da evolução da interatividade do webjornalismo entre emissores e receptores.

\section{Breves considerações sobre o público do terceiro entorno}

É possível perceber que passado o período de exaltação tecnológica, quando havia necessidade de apresentar conteúdos e formas diferentes para uma mídia nova, a história escrita pela mídia, incluindo a Internet, traz a experiência sobre o que deu e não deu certo e possibilita reflexões que podem resultar em uma comunicação democrática para e pelo público do terceiro entorno. Neste momento, a participação do usuário ainda está em ebulição por conta da polêmica gerada entre defensores e opositores em torno do open source journalism. Mas, talvez num futuro próximo, a discussão será outra e assim, sucessivamente, receptores e emissores do terceiro entorno continuarão 
a debater até chegar a um determinado ponto de amadurecimento para juntos descobrirem, por exemplo, como a notícia pode aumentar a democracia. Os meios de comunicação fazem parte do sistema social, portanto, não podemos atribuir somente a eles as mudanças sociais, culturais, econômicas e políticas. Elas também são provocadas pelo que a sociedade impõe. Neste sentido, é o público que determina como, onde e qual informação se deseja. Dessa autonomia, é que surgem novos projetos que priorizam a participação do público, às vezes por uma questão de sobrevivência e outras, ainda que raras vezes, por entender que o envolvimento do público está diretamente relacionado às exigências de uma sociedade contemporânea. Neste caso, o jornalismo participativo, em curto período de tempo, será uma prática comum, e as experiências conquistadas ao longo das transformações da mídia e dos atores sociais envolvidos também servirão para o desenvolvimento do terceiro entorno. Muito mais ativo, o público dirá com maior freqüência que vai bem, obrigado. Enquanto isso, tenta-se solucionar a crise de identidade provocada pela quantidade excessiva de informação com propostas inovadoras que ora priorizam o mediador, ora o público, e algumas alternativas que ambos são tratados em condições de igualdade.

\section{Referências:}

LEMOS, André. Cibercultura. Porto Alegre, Editora Sulina, 2002.

BRAMBILHA, Ana. OhmyNews, exemplo de jornalismo open source. Web Insider, 23/04/2005, disponível em http://webinsider.uol.com.br/vernoticia.php/id/2422. (15/07/2005)

BECKERMAN, Gal. Emerging Alternatives - edging away from Anarchy Inside the Indymedia Collective, Passion vs. Pragmatism. CRJ, New York, 2003. Disponível em http://www.cjr.org/issues/2003/5/anarchybeckerman.asp (27/07/2005)

COSTA, Luciano Martins. Jornalismo do Futuro: a hipótese da interatividade total. 14 jul. 2005, disponível em

http://observatorio.ultimosegundo.ig.com.br/artigos.asp?cod=337SAIo01. (15/07/2005). 
DE QUADROS, Claudia Irene. Periodistas y diarios electrónicos: las exigencias profesionales en la red, tesis doctoral, Universidad de La Laguna, 1999.

ECHEVERRÍA, Javier. Los señores del aire: Telépolis y el tercer entorno, Barcelona, Destino, 1999 in DELARBRE, Raúl Trejo. Telecalles, infopistas y señoríos globales, Revista Etcétera, abril de 2001, disponible em http://www.etcetera.com.mx/pag79ne6.asp.(15/03/2005).

ELIAS, Norbert. Sobre o Tempo. Rio de Janeiro, Jorge Zahar Editor, 1998.

GLAVE, James. Slashdot: All the News that Fits, Wired News, aug. 26, 1999, disponível em http://wiredvig.wired.com/news/print/o,1294,21448,00.htm. (27.07.2005).

JOHNSON, Steven. Cultura da Interface. Rio de Janeiro, Jorge Zahar Editor, 2001.

Jornalismo comunitário feito pela comunidade. Observatório da Imprensa, 27/07/2004, edição 287, disponível em http://observatorio.ultimosegundo.ig.com.br/net_arquivo.asp?edi_i=280\&edi_f=2 89\&edi=340. (12.07.2005).

KAHNEY, Leander. Citizen Reporters Make the News. Wired News, May 17, 2003, disponível em http://www.wired.com/news/culture/0,1284,58856,00.html. (12.07.2005).

LEONARD, Andrew. Open-source journalism. 8 oct. 1999, disponível em http://dir.salon.com/tech/log/1999/10/o8/geek journalism/index.html? $\underline{\text { sid= }=337901}$. (27.07.2005)

MACHADO, Elias. O ciberespaço como fonte para jornalistas. Salvador, Calandra, 2003.

NOCI, Javier Diaz. Qué pide el nuevo público. I Foro de Periodismo Digital, Caracas, Venezuela, 10 e 11 de junho, disponível em http://www.ehu.es/diaz-noci/Conf/venezuela.htm (12.07.2005).

PAVLIK, John. Journalism and New Media, New York, Columbia University Press, 2001.

PRIMO, Alex. F. T. Interação Mútua e Interação reativa: uma proposta de estudo, XXI Congresso da Intercom, Recife, PE, 9 a 12 de setembro de 1998, disponível em http://usr.psico.ufrgs.br/ aprimo/pb/espiralpb.htm. (12.07.2005)

SALAVERRÍA, R.. Diseñando el lenguaje para el ciberperiodismo [en línea]. Chasqui. Revista Latinoamericana de Comunicación, número 86, Junio de 2004, disponível em

(http://www.comunica.org/chasqui/86/salaverria86.htm). (12.07.2005) 
SANTAELLA, Lucia. Navegar no Ciberespaço - o perfil cognitivo do leitor emersivo. São Paulo, Editora Paulus, 2004.

SILVA, Juremir. A miséria do jornalismo brasileiro. As (in)certezas da mídia.Rio de Janeiro, Vozes, 2000.

VAZ, Paulo. Mediação e Tecnologia in MARTINS, Francisco Menezes e MACHADO, Juremir. Genealogia do Virtual - Comunicação, Cultura e Tecnologias do Imaginário, Editora Sulina, 2004.

WOLTON, Domique. Pensar a Internet in MARTINS, Francisco Menezes.

MACHADO, Juremir. Genealogia do Virtual - Comunicação, Cultura e Tecnologias do Imaginário, Editora Sulina, 2004. 